\title{
Coumestrol suppresses proliferation of ES2 human epithelial ovarian cancer cells
}

\author{
Whasun Lim ${ }^{1, *}$, Wooyoung Jeong ${ }^{2, *}$ and Gwonhwa Song ${ }^{1}$ \\ ${ }^{1}$ Department of Biotechnology, College of Life Sciences and Biotechnology, Korea University, Seoul 136-713, \\ Republic of Korea \\ ${ }^{2}$ Department of Animal Resources Science, Dankook University, Cheonan 330-714, \\ Republic of Korea \\ *(W Lim and W Jeong contributed equally to this work)
}

Correspondence
should be addressed
to G Song
Email
ghsong@korea.ac.kr

\begin{abstract}
Coumestrol, which is predominantly found in soybean products as a phytoestrogen, has cancer preventive activities in estrogen-responsive carcinomas. However, effects and molecular targets of coumestrol have not been reported for epithelial ovarian cancer (EOC). In the present study, we demonstrated that coumestrol inhibited viability and invasion and induced apoptosis of ES2 (clear cell-/serous carcinoma origin) cells. In addition, immunoreactive $P C N A$ and $E R B B 2$, markers of proliferation of ovarian carcinoma, were attenuated in their expression in coumestrol-induced death of ES2 cells. Phosphorylation of AKT, p70S6K, ERK1/2, JNK1/2, and p90RSK was inactivated by coumestrol treatment in a dose- and timedependent manner as determined in western blot analyses. Moreover, PI3K inhibitors enhanced effects of coumestrol to decrease phosphorylation of AKT, p70S6K, S6, and ERK1/2. Furthermore, coumestrol has strong cancer preventive effects as compared to other conventional chemotherapeutics on proliferation of ES2 cells. In conclusion, coumestrol exerts chemotherapeutic effects via PI3K and ERK1/2 MAPK pathways and is a potentially novel treatment regimen with enhanced chemoprevention activities against progression of EOC.
\end{abstract} Key Words
- ovary
- reproduction
- reproductive tract
- coumestrol
- clear cell carcinoma

Journal of Endocrinology (2016) 228, 149-160

\section{Introduction}

Phytoestrogens are natural polyphenolic compounds found mostly in soybeans, legumes, oilseeds, and nuts. Most of them have anti-estrogenic properties that may make them effective therapeutic agents. The molecular events activated by estrogen involve direct binding of estrogens to estrogen receptor alpha (ESR1) or beta (ESR2) to regulate transcription of genes after recruitment of other transcription factors such as AP1 and TF leading to proliferation, migration and invasion of cells (Heldring et al. 2007). Therefore, blocking the activity of ESR1/ESR2 in the signal transduction pathway is important for reversing development of estrogen-responsive diseases such as cancer. Structural similarities between $17 \beta$-estradiol $\left(\mathrm{E}_{2}\right)$ and phytoestrogens involve binding cytoplasmic/ nuclear ESR1/ESR2 or membrane receptors for estrogen receptors (GPER), which may prevent osteoporosis, cardiovascular diseases, neurological diseases, and hormonedependent cancers of breast, ovaries and prostate gland and menopausal symptoms (Adlercreutz 2002, Patisaul \& Jefferson 2010, Hedelin et al. 2011, Zhao \& Mu 2011). Specifically, phytoestrogens inhibit the cell cycle and have anti-inflammatory, anti-angiogenic and anti-metastatic

Published by Bioscientifica Ltd 
effects on various cancer cells (Virk-Baker et al. 2010). Phytoestrogens are classified into four main subunits including isoflavones (genistein and diadzein), lignans (enterolactone and enterodiol), coumestans (coumestrol), and stilbenes (resveratrol).

Coumestrol is a major representative of a phytoestrogen naturally found in soybeans, legumes, brussel sprouts, and spinach. It has potential therapeutic activities against carcinogenesis, neurological disorders, and autoimmune diseases through action as an antagonist to estrogen or other estrogenic chemicals for binding to ESR1/ESR2 (Schoenroth et al. 2004, Musgrove \& Sutherland 2009, de Leeuw et al. 2011). Coumestrol acts as a novel inhibitor of protein kinase CK2 which is a abundantly expressed in human cancers including epithelial ovarian cancer (EOC) and is closely linked to cell proliferation, inhibition of apoptosis and oncogenesis in various cancer cell lines from the cervix, lung and prostate, as well as leukemic cells (Ahmad et al. 2008, Duncan \& Litchfield 2008, Liu et al. 2013, Cho et al. 2014). In addition, coumestrol induces cellular senescence by stimulating production of ROS through p53-p21 ${ }^{\mathrm{Cip} 1 / \mathrm{WAF} 1}$ signal transduction cascades in breast and colon cancer cells (Lee et al. 2013). In addition, coumestrol induces expression of related genes in the endoplasmic reticulum associated with stress and inflammatory stress responses and intrinsic and extrinsic apoptosis in MCF7:5C breast cancer cells (Obiorah et al. 2014). Moreover, in hypoxic PC3 prostate cancer cells, coumestrol inhibits HIF1 $\alpha$ that is required for tumorigenesis and metastasis of solid tumors under hypoxic conditions (Cho et al. 2014).

Whereas, the most well-characterized mode of phytoestrogen action is through ESR1/ESR2 binding which induces long-term genomic effects by mediating gene transcription, phytoestrogens can also modulate a wide array of intracellular signaling cascades through binding to cell surface GPER and/or various growth factor receptors. They are known to inhibit the activity of protein tyrosine kinases which regulate transcription of estrogen receptors or recruitment of other co-transcriptional factors such as $\mathrm{AP}-1$ and $\mathrm{NF \kappa B}$, leading to suppression of tumorigenesis (Heldring et al. 2007). For example genistein, one of the phytoestrogens, affects transcriptional activity of ESR1 and ESR2 by modulating their binding affinity to estrogen-response elements (ERE) and inhibiting activity of both the PI3K/AKT and MAPK cell signaling pathways (Shimizu \& Weinstein 2005, Anastasius et al. 2009, Barnes 2010). The PI3K/AKT and MAPK signaling pathways are closely implicated in survival, growth, and proliferation of cancer cells, and their over-expression/activation have been identified in ovarian cancer patients, suggesting that these pathways are involved in ovarian cancer promotion (Yuan et al. 2000, Altomare et al. 2004, Kuo et al. 2009, Cotrim et al. 2013, Bilal et al. 2014). Thus, down-regulation/or inactivation of these pathways by phytoestrogens could inhibit ovarian carcinogenesis. Nevertheless, the molecular mechanisms of anti-cancer activity and chemoresistance induced by coumestrol in EOC are poorly understood. Ovarian cancer is the most fatal malignancy of the female reproductive tract and is the fifth leading cause of cancer deaths in women in the United States in 2015 (Siegel et al. 2015). EOC that originates from the ovarian surface epithelia is a common type of ovarian cancer accounting for about $90 \%$ of the cases and has a low 5-year survival rate (27\%) due to lack of methods for early diagnosis and early detection of symptoms (Jayson et al. 2014). EOC can be classified into four histological subtypes: serous carcinoma (SC), endometrioid carcinoma, mucinous carcinoma and clear cell carcinoma (CCC) (Kaku et al. 2003). The main treatment for EOC is cytoreductive surgery followed by platinum- or taxane-based chemotherapy. However, highgrade SC or ovarian CCC are relatively resistance to standard chemotherapy which is a combination of drugs including cisplatin (a platinum-based drug) and paclitaxel (a taxane-based drug) and poor prognosis (Tan \& Kaye 2007, Itamochi et al. 2008, Vaughan et al. 2011). Despite various difficulties in successfully treating ovarian EOC, therapeutic mechanisms for successful treatment of chemotherapy-resistant subtypes in women are clearly needed. Hence, it is necessary to identify the mechanisms responsible for resistance to cancer preventive therapies and develop new therapeutic approaches to overcome chemoresistance which prevents apoptosis through defects in signal transduction mechanisms in ovarian CCC/SC.

In the current study, we investigated the biological activity of coumestrol on various signal transduction cascades in ES2 cells. The purpose of this study was to determine: i) inhibitory effects of coumestrol on proliferation and invasion of immortalized ES2 cells; ii) the signaling mechanisms mediated by coumestrol through AKT and MAPKs pathways in ES2 cells; and iii) the cancer preventive activity of coumestrol compared with traditional cancer therapeutic regimens on ES2 cells. We hypothesized that coumestrol induces cell death in ES2 cells by suppressing PI3K/AKT and MAPK signal transduction cascades. Our findings support our hypothesis and suggest that coumestrol inhibits progression and development of EOC and that combination chemotherapy including coumestrol may increase survival rates of women with EOC.

Published by Bioscientifica Ltd. 


\section{Materials and methods}

\section{Chemicals}

Coumestrol, cisplatin and paclitaxel were purchased from Sigma-Aldrich, Inc. Rapamycin (mTOR inhibitor), SB203580 (P38 inhibitor), and U0126 (ERK1/2 inhibitor) were from Enzo Life Science (Farmingdale, NY, USA) and LY294002 (PI3K/AKT inhibitor) was from Cell Signaling Technology (Beverly, MA, USA). The antibodies against phosphorylated AKT $\left(\operatorname{Ser}^{473}\right)$, ERK1/2 $\left(\mathrm{Thr}^{202} / \mathrm{Tyr}^{204}\right)$, JNK1/2 $\left(\mathrm{Thr}^{183} / \mathrm{Thr}^{185}\right)$, p38 $\left(\mathrm{Thr}^{180} / \mathrm{Thr}^{182}\right)$, p70S6K $\left(\mathrm{Thr}^{421} / \mathrm{Ser}^{424}\right)$, p90RSK $\left(\mathrm{Thr}^{573}\right)$, and S6 $\left(\mathrm{Ser}^{235 / 236}\right)$ and total AKT, ERK1/2, JNK1/2, p38, p70S6K, p90RSK, and S6 were purchased from Cell Signaling Technology.

\section{Cell culture}

ES2 cell was purchased from the American Type Culture Collection (Manassas, VA, USA) and maintained in McCoy's 5A (Modified) Medium (Cat No.: 16600-082, Invitrogen) with $10 \%$ fetal bovine serum at $37^{\circ} \mathrm{C}$ in a $\mathrm{CO}_{2}$ incubator. For experiments, monolayer cultures of ES2 cells were grown in culture medium to $70 \%$ confluence in $100 \mathrm{~mm}$ tissue culture dishes. Cells were serum starved for $24 \mathrm{~h}$, and then treated with coumestrol. Based on preliminary dose-response experiments, $50 \mu \mathrm{M}$ of coumestrol was selected for use in all experiments in the present study. This design was replicated in three independent experiments.

\section{Proliferation assay}

Proliferation assays were conducted using Cell Proliferation ELISA, BrdU kit (Cat No.: 11647229001, Roche) according to the manufacturer's recommendations. Briefly, ES2 cells were seeded in a 96-well plate, and then incubated for $24 \mathrm{~h}$ in serum-free McCoy's 5A medium. To determine dose-dependent effects of coumestrol, cells were treated with different concentrations $(0,1,10,20$, 50 , or $100 \mu \mathrm{M}$ ) of coumestrol. For further investigations, cells were incubated in medium containing $50 \mu \mathrm{M}$ coumestrol, specific inhibitors $(20 \mu \mathrm{M}$ LY294002, $20 \mu \mathrm{M}$ SB203580, $10 \mu \mathrm{M}$ U0126, or $10 \mu \mathrm{M}$ rapamycin), $20 \mu \mathrm{M}$ paclitaxel, $50 \mu \mathrm{M}$ cisplatin or their combinations in a final volume of $100 \mu \mathrm{l} /$ well. After $48 \mathrm{~h}$ of incubation, $10 \mu \mathrm{M}$ BrdU was added to the cell culture and the cells were incubated for an additional $2 \mathrm{~h}$ at $37^{\circ} \mathrm{C}$. After labeling of cells with BrdU, the fixed cells were incubated with antiBrdU-POD working solution for $90 \mathrm{~min}$. The anti-BrdU-POD binds to BrdU incorporated into newly synthesized cellular DNA, and these immune complexes were detected by their reaction to $3,3^{\prime}, 5,5^{\prime}$-tetramethylbenzidine substrate. The absorbance values of the reaction product were quantified by measuring the absorbance at wavelengths 370 and $492 \mathrm{~nm}$ using an ELISA reader.

\section{Transwell invasion assay}

The ES2 cells $\left(1 \times 10^{5}\right.$ cells per $100 \mu$ l serum-free McCoy's $5 \mathrm{~A}$ medium) were seeded on $8-\mu \mathrm{m}$ pore Transwell inserts (Cat No.: 3422, Corning, Inc., Corning, NY, USA) and then incubated in culture medium containing $50 \mu \mathrm{M}$ coumestrol or no coumesterol ( $n=3$ wells per treatment). After $12 \mathrm{~h}$, the inserts were removed from the chamber. For evaluation of cells that migrated onto the lower surface, inserts were fixed in methanol for $10 \mathrm{~min}$. The Transwell membranes were then air-dried and stained using hematoxylin (Cat No.: HHS32, Sigma-Aldrich, Inc.) for $30 \mathrm{~min}$. The insert membranes were washed gently several times with tap water to remove excess stain. The cells on the upper side of the inserts were removed with a cotton swab. The Transwell membranes were removed and placed on a glass slide with the side containing cells facing up, and the slide covered with Permount solution. Migrated cells were counted in five non-overlapping locations, which covered $\sim 70 \%$ of the insert membrane growth area, using a DM3000 (Leica) microscope. The entire experiment was repeated at least three times.

\section{TUNEL assay}

The ES2 cells $\left(3 \times 10^{4}\right.$ cells per $\left.300 \mu \mathrm{l}\right)$ were seeded on confocal dishes (Cat No.: 100350, SPL Life Science, Seoul, Republic of Korea) and then incubated for $24 \mathrm{~h}$ in serumfree McCoy's 5A medium. Cells were then treated with coumestrol at a final concentration of $50 \mu \mathrm{M}$ for $48 \mathrm{~h}$ at $37^{\circ} \mathrm{C}$ in a $\mathrm{CO}_{2}$ incubator. After incubation, the cells were air dried and fixed with 4\% paraformaldehyde in PBS for $1 \mathrm{~h}$ at room temperature. The cells were rinsed with PBS briefly and permeabilized using $0.1 \%$ Triton X-100 in $0.1 \%$ sodium citrate for $2 \mathrm{~min}$ on ice. Then, the cells were subjected to TUNEL staining mixture using the In Situ Cell Death Detection kit, TMR red (Roche) for $1 \mathrm{~h}$ at $37^{\circ} \mathrm{C}$ in the dark. Cells were then washed with PBS and overlaid with DAPI (Cat No.: D8417, Sigma). Fluorescence was detected using a LSM710 (Carl Zeiss, Oberkochen, Germany) confocal microscope fitted with a digital microscope AxioCam camera with Zen2009 software. Visualization of TUNEL-positive cells allowed assessment

Published by Bioscientifica Ltd 
of changes in apoptotic cell numbers and total numbers of cells in culture using DAPI to stain nuclei. TUNEL-positive cells were identified using confocal imaging.

\section{Immunofluorescence microscopy}

The effects of coumestrol on the expression of PCNA and ERBB2 were determined by immunofluorescence microscopy. The ES2 cells $\left(3 \times 10^{4}\right.$ cells per $\left.300 \mu \mathrm{l}\right)$ were seeded on confocal dishes (Cat No.: 100350, SPL Life Science) and then incubated for $24 \mathrm{~h}$ in serum-free McCoy's 5A medium. The serum starved cells were treated with coumestrol for $30 \mathrm{~min}$ and then probed with mouse anti-human monoclonal PCNA (Cat No.: sc-56, Santa Cruz Biotechnology) at a final dilution of 1:100 $(2 \mu \mathrm{g} / \mathrm{ml})$ and mouse anti-human monoclonal ERBB2 (Cat No.: MS599-P1, Thermo Fisher Scientific, Waltham, MA, USA) at a final dilution of 1:200 $(1 \mu \mathrm{g} / \mathrm{ml})$. They were then incubated with goat anti-mouse IgG Alexa 488 (Cat No.: A-11001, Invitrogen) at a 1:200 dilution for $1 \mathrm{~h}$ at room temperature. Cells were then washed using $0.1 \%$ BSA in PBS and overlaid with DAPI. For each primary antibody, images were captured using a LSM710 (Carl Zeiss) confocal microscope and nuclear size and morphology of fluorescent-stained cells and localization of fluorescence proteins in the cells were analyzed.

\section{Western blot analysis}

Whole-cell lysates were obtained from cells following treatment with RIPA buffer containing protease inhibitor cocktails (Roche). Concentrations of protein in whole-cell extracts were determined using the Bradford protein assay (Bio-Rad) with BSA as the standard. Twenty micrograms denatured proteins were loaded, separated using SDS-PAGE and then transferred to nitrocellulose. Blots were developed using enhanced chemiluminescence detection (SuperSignal West Pico, Pierce, Rockford, IL, USA) and quantified by measuring the intensity of light emitted from correctly sized bands under ultraviolet light using a ChemiDoc EQ system and Quantity One software (Bio-Rad). Immunoreactive proteins were detected using goat anti-rabbit polyclonal antibodies against phospho-proteins and total-proteins at a 1:1000 dilution and 10\% SDS/PAGE gel. As a loading control, total proteins were used to normalize results from detection of proteins by western blotting. All antibodies were from Cell Signaling Technology. Multiple exposures of each western blot were performed to ensure linearity of chemiluminescent signals.
Signal intensities of phosphorylated (p)-proteins in blot images were normalized based on the signal intensity from total protein. For analyses of dose-dependent and time-dependent effects, fold-changes in the normalized abundance of p-proteins were determined in comparison to control cells (first lane in all blots). Data from at least three independent experiments were used to calculate means \pm s.E.M.

\section{Statistical analysis}

Data from western blot analyses, proliferation and invasion assays were subjected to ANOVA according to the general linear model (PROC-GLM) of the SAS program (SAS Institute, Cary, NC, USA) to determine whether there were significant effects on abundance of p-proteins, proliferation or invasion of ES2 cells in response to treatments. Differences with a probability value of $P<0.05$ were considered statistically significant. Data are presented as mean \pm s.E.M. unless otherwise stated.

\section{Results}

\section{Coumestrol suppresses cellular activities of ES2 cells}

To determine the action of coumestrol on ES2 cells from human ovary, we measured cell proliferation of ES2 cells treated with coumestrol in a dose-dependent manner $(0,1,10,20,50$, and $100 \mu \mathrm{M})$ as illustrated in Fig. 1A. Coumestrol suppressed proliferation of ES2 cells in a dose-dependent manner with $\mathrm{IC}_{50}$ being $50 \mu \mathrm{M}$ $(P<0.01)$. Using this concentration of coumestrol, we investigated the effect of coumestrol on invasiveness of ES2 cells by Transwell invasion analyses (Fig. 1B and C). Coumestrol treatment of ES2 cells decreased invasiveness by $\sim 57 \%(P<0.001)$ compared to non-treated ES2 cells. As shown in Fig. 1D, coumestrol induced DNA fragmentation leading to apoptosis of ES2 cells as evidenced by red fluorescence in the nucleus. On the other hand, apoptotic cells were not detected in the untreated ES2 control cells. These results reveal that the coumestrol possesses anticarcinogenic effects on ES2 cells, such as attenuating proliferation and migration of ES2 cells.

\section{Coumestrol inhibits expression of PCNA and ERBB2 in ES2 cells}

Next, we determined the expression of representative markers of proliferation of ovarian cancer such as PCNA and ERBB2 between coumestrol-treated and untreated ES2

Published by Bioscientifica Ltd. 


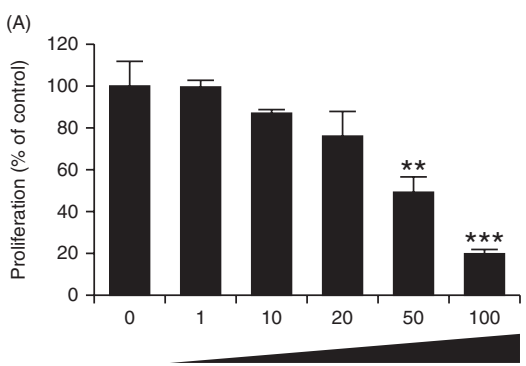

Coumestrol $(\mu \mathrm{M})$

(D)

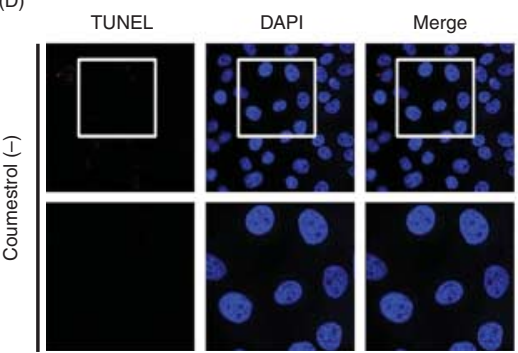

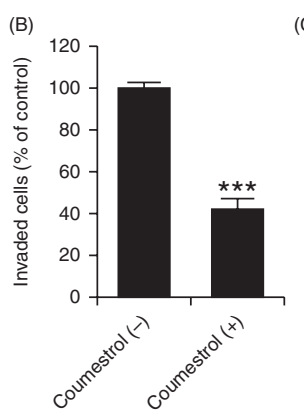

(C)
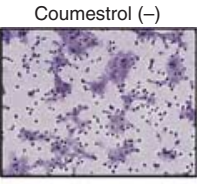

Coumestrol $(+)$
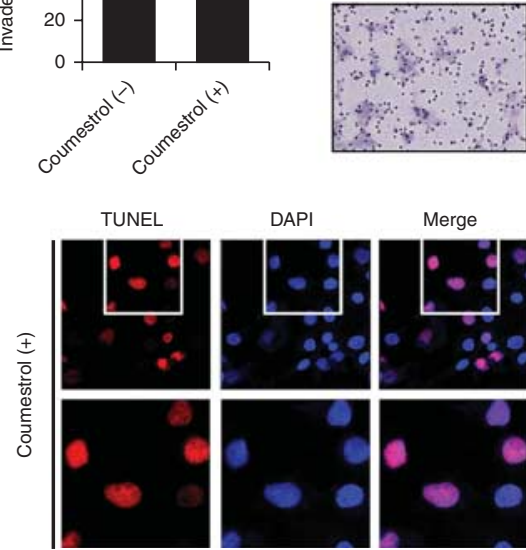

Figure 1

Antiproliferative effects of coumestrol on ES2 cells. (A) Coumestrol decreased viability of ES2 cells in a dose-dependent manner. Data were analyzed as percentage change relative to non-treated control ES2 cells $(100 \%)$. (B and C) Transwell invasion analyses indicated that coumestrol suppressed invasion of ES2 cells compared with non-treated ES2 cells. The number of invaded cells is presented as the percentage of invaded cells

cells by immunofluorescence analyses (Fig. 2). PCNA was mainly localized in the nucleus in ES2 cells, but its expression was detected only faintly in nuclei of coumestrol-treated ES2 cells. Expression of ERBB2 in ES2 cells was

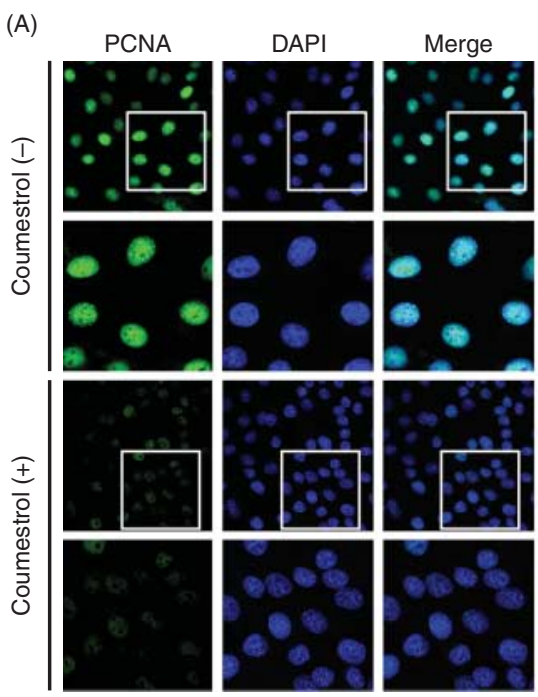

with respect to untreated control cells. (D) TUNEL-positive apoptotic cells (red) were detected only in ES2 cells treated with coumestrol. The nuclei of cells were counterstained with DAPI (blue). The asterisks indicates an effect of treatment $(* * P<0.01$ and $* * * P<0.001)$. A full colour version of this figure is available at http://dx.doi.org/10.1530/JOE-15-0418.

also decreased by coumestrol compared with non-treated ES2 cells which had abundant expression in the plasma membrane. These results indicate that coumestrol reduces proliferative activity of ES2 cells.

(B)

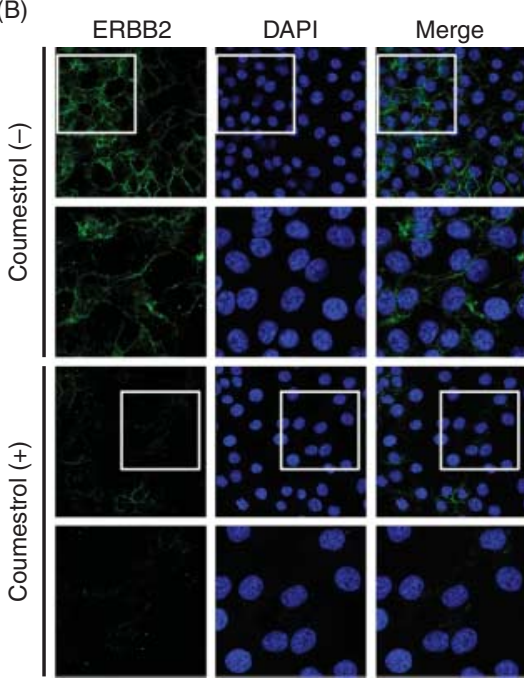

Figure 2

Immunofluorescence analyses for PCNA and ERBB2 in ES2 cells treated with coumestrol. Immunoreactive PCNA (A) and ERBB2 (B) proteins were detectable in very low abundance in nuclei and cell membranes of coumestrol-treated ES2 cells, whereas those proteins were abundant

in non-treated ES2 cells. Images were captured at $40 \times$ and $80 \times$ objective magnification. A full colour version of this figure is available at http://dx.doi.org/10.1530/JOE-15-0418. 
(A)

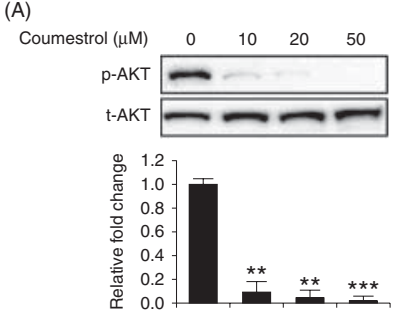

(D)

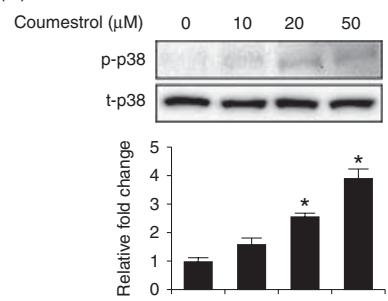

(B)

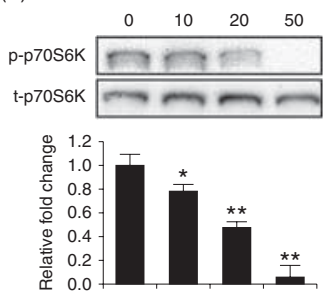

(E)

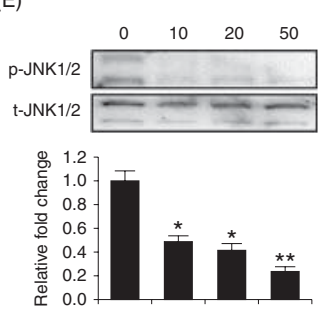

(C)

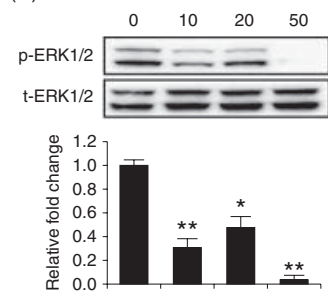

(F)

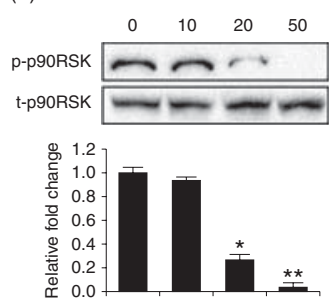

\section{Figure 3}

Analyses of dose-dependent effects of coumestrol on phosphorylation of molecular target proteins in response to coumestrol in the ES2 cells. Monolayers of $70 \%$ confluent ES2 cells were incubated with serum-free media for $24 \mathrm{~h}$ and then treated with coumestrol $(0,10,20$, and $50 \mu \mathrm{M})$ for 30 min. Phosphorylation of AKT (A), p70S6K (B), ERK1/2 (C), p38 (D), JNK1/2

\section{Coumestrol reduces phosphorylation of PI3K/AKT and MAPK in ES2 cells}

To investigate the effect of coumestrol on the PI3K/AKT and MAPK signaling pathways in ES2 cells, we performed western blot analyses in a dose- $(0,10,20$ and $50 \mu \mathrm{M})$ and time- $(0,5,15,30,60$, and $120 \mathrm{~min})$ dependent manner. As illustrated in Fig. 3, coumestrol decreased the abundance of phosphorylated AKT, -p70S6K, -ERK1/2, -JNK1/2 and -p90RSK in ES2 cells in a dose-dependent manner. However, the phosphorylation of p38 increased in response to coumesterol treatment of ES2 cells. The results were that phosphorylated AKT increased at $5 \mathrm{~min}$ after coumestrol treatment and then decreased significantly after $15 \mathrm{~min}$ of coumestrol treatment (Fig. 4A). Phosphorylation of p70S6K increased at $15 \mathrm{~min}$ of coumestrol treatment of ES2 cells, but then decreased significantly after 30 min of incubation of ES2 cells with coumestrol (Fig. 4B). To identify the signaling mechanism mediated by coumestrol in ES2 cells, we confirmed the phosphorylation of S6, which is downstream of p70S6K in ES2 cells incubated coumestrol (Fig. 4C). Phosphorylation of S6 was abundant in non-treated ES2 cells, but phosphorylated-S6 was decreased in a time-dependent manner in response to treatment of ES2 cells with coumesterol. In addition, phosphorylated ERK1/2 and JNK1/2 decreased significantly after $15 \mathrm{~min}$ and $5 \mathrm{~min}$ of coumestrol incubation respectively compared with basal
(E), and P90RSK (F) was determined in ES2 cells treated with coumestrol using western blot analyses. Blots were imaged to estimate relative changes in abundance of phosphorylated protein relative to total protein. The asterisks denote statistically significant effects of treatment $\left({ }^{*} P<0.05, * * P<0.01\right.$ and $\left.* * * P<0.001\right)$.

levels (Fig. 4D and E). Similarly, the abundance of phosphorylated-p90RSK decreased in a time-dependent manner in ES2 cells treated with coumestrol (Fig. 4F). These results indicate that coumestrol suppresses activity of protein kinases related in PI3K and MAPK signaling mechanism in a dose- and time-dependent manner.

PI3K/AKT and MAPK signaling decreases phosphorylation of AKT, p70RSK, S6, and ERK1/2 in ES2 cells treated with coumestrol

To identify cell signaling pathways mediated by coumestrol, ES2 cells were pretreated with specific inhibitors of PI3K (LY294002, $20 \mu \mathrm{M}$ ), p38 MAPK (SB203580, $20 \mu \mathrm{M}$ ) and ERK1/2 MAPK (U0126, $10 \mu \mathrm{M})$ pathways individually or in combination prior to treatment with coumestrol. Treatment of ES2 cells with LY294002, SB203580, or U0126 along with coumestrol had greater effects of coumestrol to inhibit phosphorylation of AKT compared with coumestrol treatment only, but the effects were not statistically significant $(P>0.05)$ (Fig. 5A). The reduced abundance of $\mathrm{p}$-AKT proteins in coumestrol treated cells declined further $(P<0.05)$ in cells treated with coumestrol plus all three inhibitors, as compared with that for treatment of cells with coumestrol alone- or coumestrol plus LY294002. Treatment of ES2 cells with LY294002 or U0126 along with coumestrol reduced tendencies for

Published by Bioscientifica Ltd 
(A)

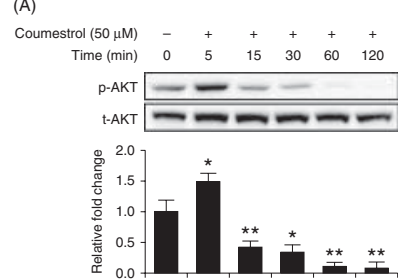

(C)

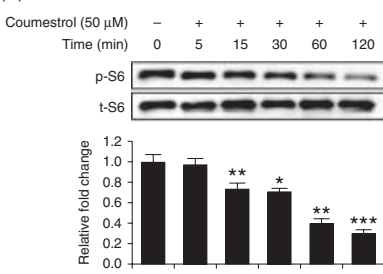

(E)

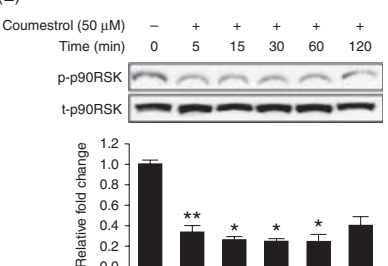

(B)

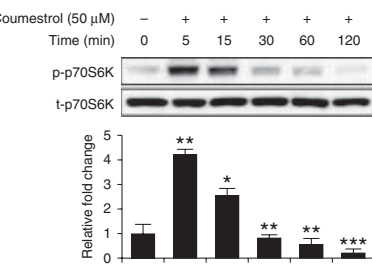

(D)

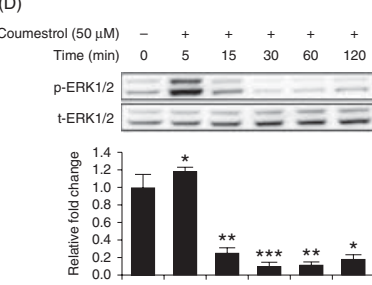

( $\mathrm{F})$

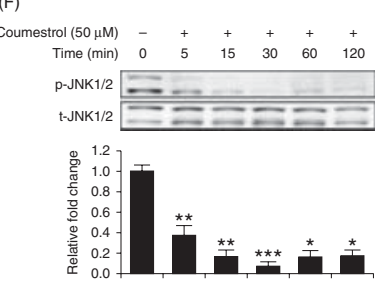

Figure 4

Analyses of time-dependent effects of coumestrol and phosphorylation of cell signaling proteins in ES2 cells. Monolayers of $70 \%$ confluent ES2 cells were incubated with serum-free media for $24 \mathrm{~h}$ and then treated with coumestrol $(50 \mu \mathrm{M})$ for the times indicated $(0,5,15,30,60$, and $120 \mathrm{~min})$. Phosphorylation of AKT (A), p70S6K (B), S6 (C), ERK1/2 (D), p90RSK (E), and JNK 1/2 (F) were detected in ES2 cells in the presence of coumestrol at the time indicated by western blot analyses. Blots were imaged to estimate the normalized values by measurements of expressed levels of each phosphorylated protein relative to total protein. The asterisks denote statistically significant differences $(* P<0.05, * * P<0.01$ and $* * * P<0.001)$.

coumestrol to decrease p-p70S6K and p-S6 abundance compared with coumestrol treatment only, but the effect was not statistically significant $(P>0.05)$ (Fig. 5B and C). The reduced abundance of $\mathrm{p}-\mathrm{S6}$ proteins in coumestrol treated cells declined further $(P<0.05)$ when cells were treated with coumestrol plus inhibitor combinations (LY294002 plus SB203580, LY294002 plus U0126, all three inhibitors), compared with that for cells treated with coumestrol alone. However, SB203580 or U0126 plus coumestrol did not influence the abundance of phosphorylated p70S6K or -S6 as compared with coumestrol treatment alone. Furthermore, reduced abundance of p-ERK $1 / 2$ in the presence of coumestrol decreased more in ES2 cells in response to additional treatments with LY294002, U0126 or the combination of inhibitors with coumestrol, whereas additional treatment with SB203580 did not affect the abundance of p-ERK1/2 (Fig. 5D). These results show that inhibition of p70RSK and S6 activation

by coumestrol on ES2 cells could be partly through inactivation of PI3K/AKT and ERK1/2 MAPK which ultimately suppresses protein synthesis and proliferation of ES2 cells.

\section{PI3K/AKT/mTOR and MAPK inhibitors inhibit proliferative activity of ES2 cells treated with coumestrol}

To support the association between coumestrol-mediated PI3K/AKT/mTOR, ERK1/2 MAPK and p38 MAPK cell signaling and the influence of coumestrol on ES2 cell proliferation, we conducted cell proliferation assays in the presence or absence of coumestrol, LY294002, SB203580, U0126, and rapamycin (mTOR inhibitor, $10 \mu \mathrm{M}$ ) (Fig. 6). Consistent with previous results, coumestrol reduced the proliferation of ES2 cells by about $50 \%(P<0.01)$.

(A)

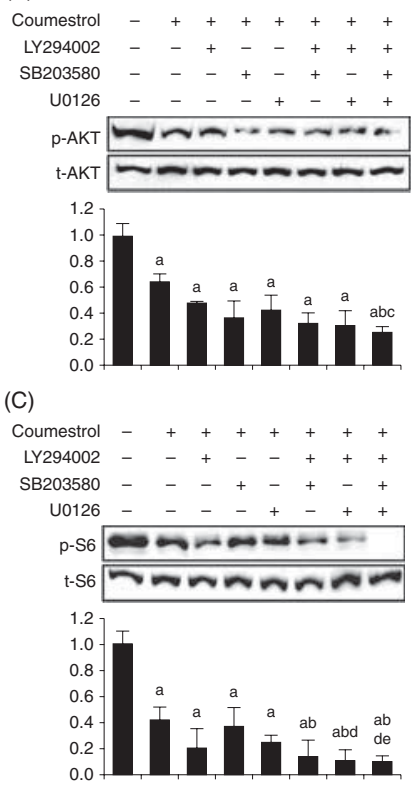

(B)

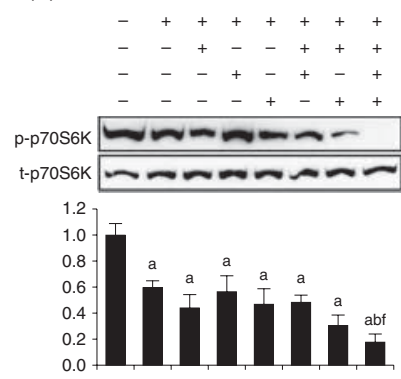

(D)

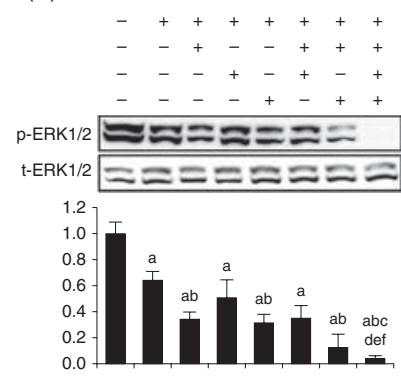

Figure 5

Actions of various pharmacological inhibitors in the absence of presence of coumestrol on phosphorylation of cell signaling proteins. Starved ES2 cells were incubated in serum-free medium with LY294002 (PI3K inhibitor, $20 \mu \mathrm{M})$, SB203580 (p38 MAPK inhibitor, $20 \mu \mathrm{M}$ ), U0126 (ERK1/2 MAPK inhibitor, $10 \mu \mathrm{M}$ ) or rapamycin (mTOR inhibitor, $10 \mu \mathrm{M})$ or a combination of those inhibitors for $1 \mathrm{~h}$ and then incubated with coumestrol $(50 \mu \mathrm{M})$ for 30 min. Phosphorylation of AKT (A), p70S6K (B), S6 (C), and ERK1/2 (D) were detected in ES2 cells by western blot analyses. Blots were imaged to estimate the normalized values of each phosphorylated protein relative to total protein. Different lowercase letters indicate statistically significant changes $(P<0.05)$ between treatments; a, compared with non-treatment (lane 1); b, compared with coumestrol only treatment (lane 2); c, compared with coumestrol + LY294002 treatment (lane 3); d, compared with coumestrol + SB203580 treatment (lane 4); e, compared with coumestrol+ U0126 treatment (lane 5); f, compared with coumestrol + LY294002 + SB203580 treatment (lane 6). 


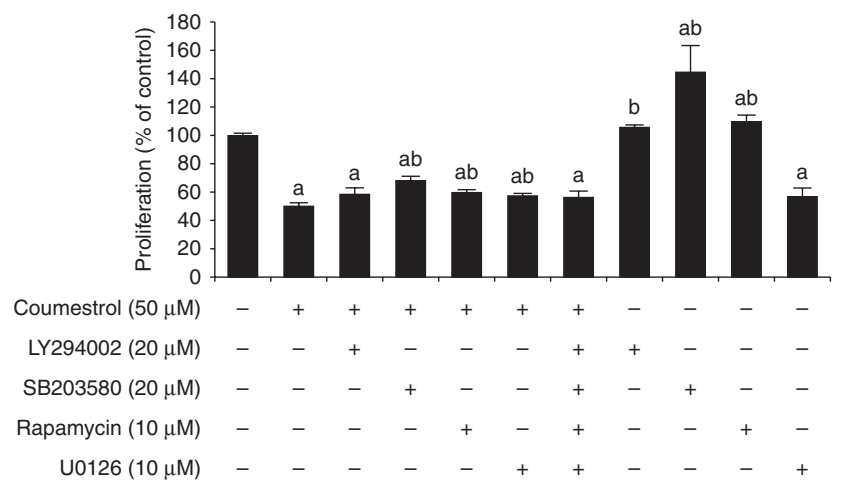

Figure 6

Effect of pharmacological inhibitors of cell signaling proteins on proliferation of ES2 cells treated with coumestrol. The ES2 cells were starved for $24 \mathrm{~h}$ with serum-free media and treated with coumestrol $(50 \mu \mathrm{M})$, LY294002 $(20 \mu \mathrm{M}), \mathrm{SB} 203580(20 \mu \mathrm{M}), \mathrm{U} 0126(10 \mu \mathrm{M})$, or rapamycin $(10 \mu \mathrm{M})$ or a combination of coumestrol and each inhibitor for $48 \mathrm{~h}$. Proliferation assay analyses revealed changes in numbers of cells due to each treatment and data represent relative changes in cell proliferation compared to non-treated control cells set at $100 \%$. All quantitative data are presented as LSM with overall S.E.M. Different lowercase letters indicate statistically significant changes $(P<0.05)$ between treatments; a, compared with non-treatment (lane 1); b, compared with coumestrol only treatment (lane 2).

Treatment of SB203580 rapamycin $(P<0.01)$ or U0126 $(P<0.05)$ before incubation of ES2 cells with coumestrol slightly increased the ES2 cell proliferation compared to coumestrol treatment alone. On the other hand, SB203580 or rapamycin alone increased proliferation of ES2 cells compared with non-treated cells, and the effects of SB203580 and rapamycin were inhibited when cells were also co-treated with coumestrol. In comparison with non-treated cells, treatment of ES2 cells with LY294002 alone did not have a significant effect on cell proliferation, while co-treatment of coumestrol and LY294002 decreased cell proliferation. There were no differential changes in proliferation of ES2 cells between U0126 plus or minus coumestrol. These results indicate that coumestrol has greater anti-proliferative effects on ES2 cells than blockage of PI3K and MAPK signal transduction cascades.

\section{Coumestrol possesses cancer preventive effects on ES2 cells as compared with cisplatin and paclitaxel}

To estimate cytotoxicity of coumestrol against ES2 cells, we investigated viability of ES2 cells treated with coumestrol, paclitaxel (a taxane-based agent) or cisplatin (a platinum-based agent) and the combination of these chemicals. As illustrated in Fig. 7, a monotherapy with coumestrol $(50 \mu \mathrm{M})$, paclitaxel $(20 \mu \mathrm{M})$ or cisplatin
$(50 \mu \mathrm{M})$ inhibited $(P<0.05)$ proliferation of ES2 cells by 54,70 , and $64 \%$ compared with non-treated ES2 control cells $(100 \%)$. In comparison between monotherapy treatments, coumestrol alone had a greater effect to reduce cell proliferation than either paclitaxel- or cisplatin alone. In addition, the combined therapies using coumestrol plus paclitaxel, coumestrol plus cisplatin, and coumestrol plus paclitaxel plus cisplatin) suppressed $(P<0.05)$ survival of ES2 cells compared with non-treated ES2 cells. Specifically, coumestrol increased sensitivity of ES2 cells to paclitaxel as evidenced by a $21 \%$ decrease $(P<0.05)$ in cell proliferation compared with treatment with paclitaxel alone. These results suggest that monotherapy with coumestrol is as effective as conventional chemotherapies including paclitaxel or cisplatin and that coumestrol may be more effective than paclitaxel-based chemotherapy for treatment of EOC.

\section{Discussion}

Coumesterol is a phytoestrogen known to act as an antagonist to estrogen and other estrogenic chemicals for binding to ESRs/GPER (Musgrove \& Sutherland 2009, de Leeuw et al. 2011). Based on epidemiological analyses, coumestrol from soybean products may reduce the incidence of EOC (Bandera et al. 2011). However, the signal transduction mechanism whereby coumestrol

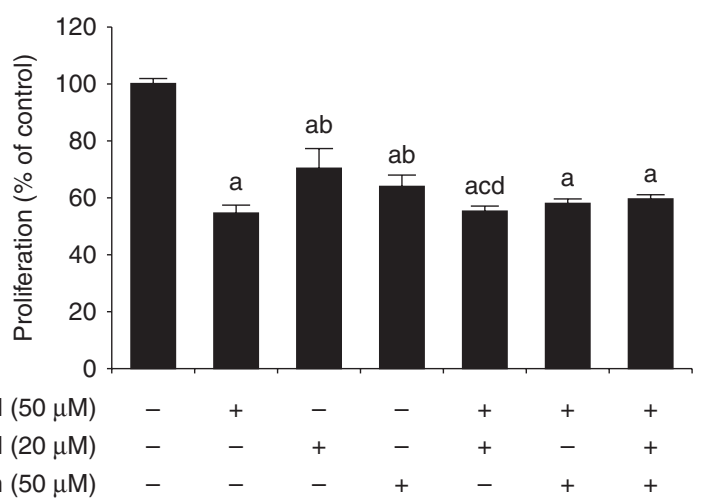

\section{Figure 7}

Comparison of chemotherapeutic effects of coumestrol alone versus coumestrol and cisplatin or paclitaxel on proliferation of ES2 cells. The starved ES2 cells were treated with coumestrol $(50 \mu \mathrm{M})$, paclitaxel $(20 \mu \mathrm{M})$ or cisplatin $(50 \mu \mathrm{M})$ or their combinations for $48 \mathrm{~h}$. Data from the cell proliferation assay represent changes in proliferation in comparison to non-treated control cells that were set to $100 \%$. All quantitative data are presented as the LSM with overall S.E.M. Different lowercase letters indicate statistically significant changes $(P<0.05)$ between treatments; a, compared with non-treatment (1st bar); b, compared with coumestrol only treatment (2nd bar); c, compared with paclitaxel only treatment (3rd bar);

d, compared with cisplatin only treatment (4th bar).

Published by Bioscientifica Ltd. 


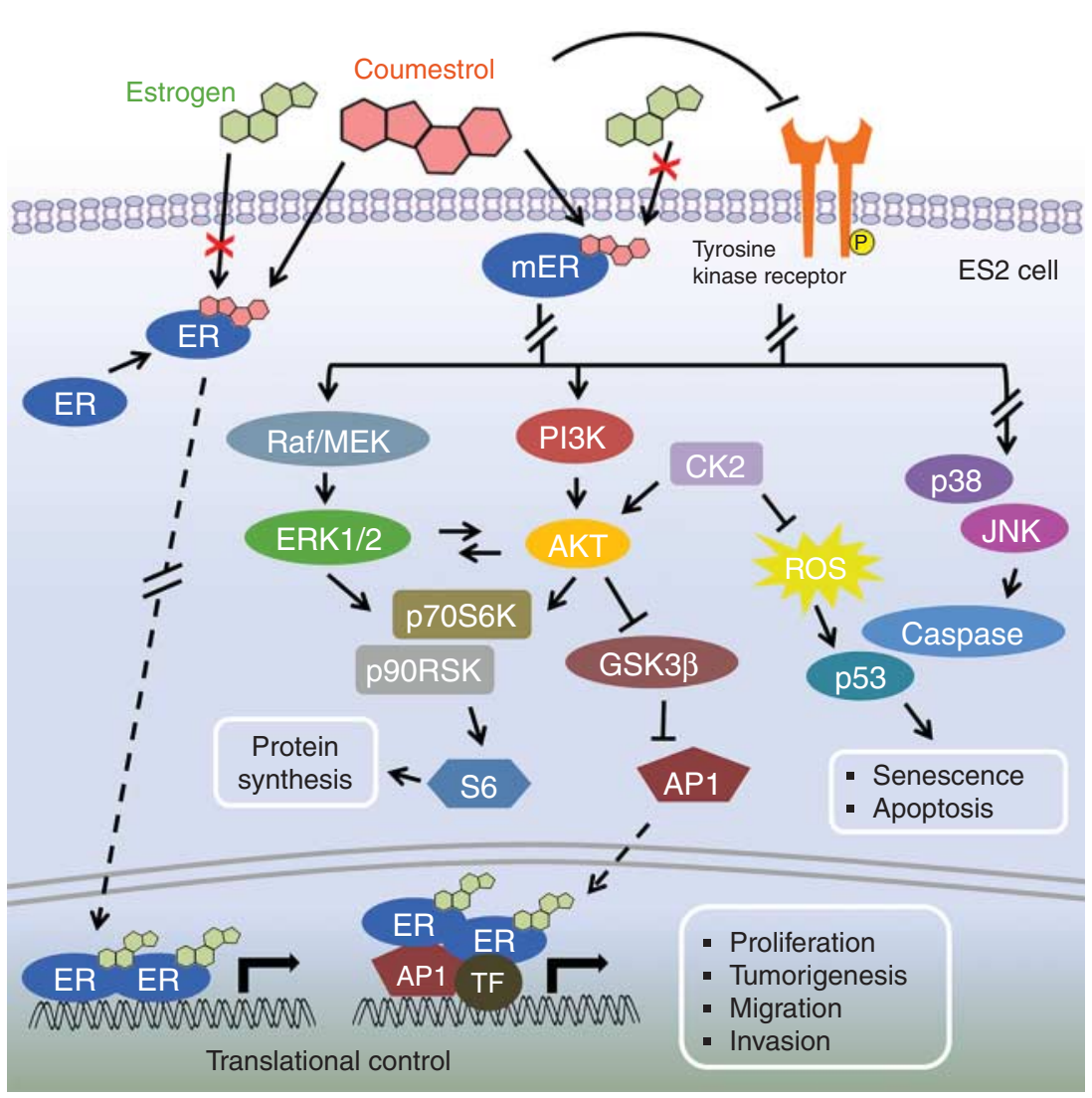

\section{Figure 8}

Hypothetical model illustrating the cancer preventive action by coumestrol in ES2 human epithelial ovarian cancer cells. A full colour version of this figure is available at http://dx.doi.org/10.1530/JOE-15-0418.

functions to reduce EOC is not known. In the present study, we determined the effects of coumestrol on proliferation of ES2 cells. As illustrated in Fig. 1, coumestrol suppressed viability and invasivness while increasing apoptosis of ES2 cells. To eliminate potential cytotoxic effects of coumesterol in invasion assays, the cells were treated with coumestrol for only $12 \mathrm{~h}$ which is less than the doubling time of ES2 cells and too short of an exposure time to significantly affect proliferation of ES2 cells. Although, these results support that inhibition of invasion/migration by coumestrol independent of cytotoxic effects, potential influences of coumesterol on cell proliferation cannot be ruled out completely. Moreover, coumestrol decreased expression of markers of cell proliferation, PCNA, and ERBB2, in ES2 cells. Expression of PCNA and ERBB2 is abundant in the advanced stages of ovarian carcinoma (Khalifa et al. 1994). Specifically, increases in PCNA activate cell proliferation through cell cycle regulation which leads to poor survival rates for EOC patients. In addition, ERBB2 amplification is frequently detected in clear cell types of ovarian cancer (Fujimura et al. 2002). Thus, inhibition of proliferation, invasion, expression of genes regulating cell proliferation and enhanced apoptosis were signature effects of coumesterol on ES2 cells.

The results of this study suggest that the antiproliferative activity of coumestrol on ES2 cell is a consequence of increasing apoptotic signaling pathways through inactivation of phosphorylation of signaling molecules in the PI3K-AKT-mTOR and ERK1/2 and JNK1/2 MAPK pathways. In the development of EOC, blockage of expression of downstream protein kinases of the PI3K signal transduction pathway prolongs diseasefree interval and enhances overall survival in patients with ovarian CCC (Jin et al. 2014). Moreover, the RAS-MEK-ERK pathway activated by EGFR is considered a potential therapeutic target for ovarian CCC (Bartholomeusz et al. 2012). A tyrosine kinase inhibitor (erlotinib) that acts on the EGFR and a MEK inhibitor (selumetinib) suppress proliferation of CCC cells through reduction of phosphorylated ERK1/2 and induction of $\mathrm{G}_{1}$ arrest. Furthermore, a dual inhibitor of PI3K/mTOR signaling can

Published by Bioscientifica Ltd. 
overcome drug resistance of ovarian CCC (Oishi et al. 2014). In the present study, we assessed effects of pharmacological inhibitors including LY294002 (PI3K inhibitor), SB203580 (p38 MAPK inhibitor), and U0126 (ERK1/2 inhibitor) on coumestrol-reduced phosphorylation of signaling molecule in ES2 cells with respect to roles of PI3K and MAPK signaling pathways on coumestrol-induced apoptosis. Our results revealed that the combined treatment of coumestrol and LY294002 reduced the activity of phosphor-AKT, -p70S6K, -S6 and -ERK1/2 compared with a single treatment of ES2 cells with coumestrol. AKT signaling is frequently activated in cisplatin-resistant cells of ovarian CCC and phosphorylates $\mathrm{p} 70 \mathrm{~S} 6 \mathrm{~K}$ and $\mathrm{S} 6$ stimulating translation of proteins required for cell proliferation and migration (Schmelzle \& Hall 2000, Mabuchi et al. 2009). In addition, AKT and ERK1/2 often converge to phosphorylate the same protein kinases by promoting cross-talk (Mendoza et al. 2011). On the other hand, a synergistic effect was not observed for ES2 cell proliferation when coumestrol was combined with LY294002, SB203580, U0126, or rapamycin (mTOR inhibitor) even though these pharmacological inhibitors enhanced chemopreventive effects of ovarian CCC. Taken together these results suggest that coumestrol may effectively reverse development of CCC in human ovaries.

The resistance of ovarian CCC to platinum-based regimens is considered a principle clinical problem in the management of that disease. To improve the response and survival rates of CCC patients, combination chemotherapy using paclitaxel with a platinum-based agent is commonly used as a standard first-line therapy after surgical cytoreduction (Thigpen et al. 1994). In the present study, we compared the therapeutic activity of coumestrol with traditional chemotherapeutic agents including paclitaxel and cisplatin. Results of this study indicated that the chemopreventive efficacy of coumestrol on proliferation of ES2 cells was greater than that of either cisplatin or paclitaxel. Moreover, the combination of the anti-cancer therapeutics with coumestrol decreased viability of ES2 cells compared to the conventional single agent treatment. These results suggest that coumestrol may be a natural chemopreventive agent against the proliferation of chemotherapy resistant-ovarian cancer cells. However, clinical trials are required for development of dietary supplements or other regimens for treatment of patients with ovarian cancer with coumestrol. Since the ES2 cell line was established in the late 1980s, the cell line has been widely used in studies of ovarian CCC. The significant molecular and biological features of ovarian CCC are mutations of ARID1A or PIK3CA, positive staining for
HNF1 $\beta$ and similarities in gene expression profiles with endometrial cancer and renal CCC (del Carmen et al. 2012). However, recent studies question the use of ES2 cells as representative of CCC and suggest that the cell line is more likely of SC origin, based on unusual features distinct from other ovarian CCC (Domcke et al. 2013). Further investigation is needed to elucidate more precisely the subtype-specific roles and signaling mechanisms of coumestrol.

In conclusion, results of this study provide the first in vitro evidence of chemotherapeutic activity by coumestrol for treatment of human EOC. Coumestrol suppressed survival rates of ES2 cells via inhibition of proliferation and invasion and stimulated apoptosis. In addition, coumestrol blocked phosphorylation and activation of PI3K/AKT and RAS/MAPKs cell signaling pathways in ES2 cells as illustrated in Fig. 8. Also, a combination of coumestrol and current anti-cancer drugs could lead to a more effective and less harmful treatment of ovarian $\mathrm{CCC} / \mathrm{SC}$. Therefore, these results suggest that coumestrol has great potential as a cancer preventive therapeutic for treatment of human EOC.

Declaration of interest

The authors declare that there is no conflict of interest that could be perceived as prejudicing the impartiality of the research reported.

\section{Funding}

This research was supported by a grant of the Korea Health Technology R\&D Project through the Korea Health Industry Development Institute funded by the Ministry of Health \& Welfare (grant number: HI15C0810). This research was also funded by the Basic Science Research Program (2015R1D1A1A01059331 and 2014R1A1A2059493) and a Korea University Grant, Korea University, Republic of Korea.

\section{Author contribution statement}

W L, W J, and G S were responsible for supervision the experiment, analysis of the gene expression, statistical analysis of all data, and preparation of the manuscript. $W \mathrm{~L}$ and $\mathrm{W} J$ were responsible for collection of all animal samples and performing all experiments.

\section{Acknowledgements}

We appreciate Dr Fuller W Bazer (Texas A\&M University, USA) for thoughtful editing and comments on our paper.

\section{References}

Adlercreutz H 2002 Phyto-oestrogens and cancer. Lancet. Oncology 3 364-373. (doi:10.1016/S1470-2045(02)00777-5)

Published by Bioscientifica Ltd 
Ahmad KA, Wang G, Unger G, Slaton J \& Ahmed K 2008 Protein kinase CK2 - a key suppressor of apoptosis. Advances in Enzyme Regulation 48 179-187. (doi:10.1016/j.advenzreg.2008.04.002)

Altomare DA, Wang HQ, Skele KL, De Rienzo A, Klein-Szanto AJ, Godwin AK \& Testa JR 2004 AKT and mTOR phosphorylation is frequently detected in ovarian cancer and can be targeted to disrupt ovarian tumor cell growth. Oncogene 23 5853-5857. (doi:10.1038/sj.onc.1207721)

Anastasius N, Boston S, Lacey M, Storing N \& Whitehead SA 2009 Evidence that low-dose, long-term genistein treatment inhibits oestradiolstimulated growth in MCF-7 cells by down-regulation of the PI3-kinase/Akt signalling pathway. Journal of Steroid Biochemistry and Molecular Biology 116 50-55. (doi:10.1016/j.jsbmb.2009.04.009)

Bandera EV, King M, Chandran U, Paddock LE, Rodriguez-Rodriguez L \& Olson SH 2011 Phytoestrogen consumption from foods and supplements and epithelial ovarian cancer risk: a population-based case control study. BMC Women's Health 11 40. (doi:10.1186/ 1472-6874-11-40)

Barnes S 2010 The biochemistry, chemistry and physiology of the isoflavones in soybeans and their food products. Lymphatic Research and Biology 8 89-98. (doi:10.1089/lrb.2009.0030)

Bartholomeusz C, Oishi T, Saso H, Akar U, Liu P, Kondo K, Kazansky A, Krishnamurthy S, Lee J, Esteva FJ et al. 2012 MEK1/2 inhibitor selumetinib (AZD6244) inhibits growth of ovarian clear cell carcinoma in a PEA-15-dependent manner in a mouse xenograft model. Molecular Cancer Therapeutics 11 360-369. (doi:10.1158/1535-7163. MCT-11-0400)

Bilal I, Chowdhury A, Davidson J \& Whitehead S 2014 Phytoestrogens and prevention of breast cancer: the contentious debate. World Journal of Clinical Oncology 5 705-712. (doi:10.5306/wjco.v5.i4.705)

del Carmen MG, Birrer M \& Schorge JO 2012 Clear cell carcinoma of the ovary: a review of the literature. Gynecologic Oncology 126 481-490. (doi:10.1016/j.ygyno.2012.04.021)

Cho SY, Cho S, Park E, Kim B, Sohn EJ, Oh B, Lee EO, Lee HJ \& Kim SH 2014 Coumestrol suppresses hypoxia inducible factor $1 \alpha$ by inhibiting ROS mediated sphingosine kinase 1 in hypoxic PC-3 prostate cancer cells. Bioorganic \& Medicinal Chemistry Letters 24 2560-2564. (doi:10.1016/j. bmcl.2014.03.084)

Cotrim CZ, Fabris V, Doria ML, Lindberg K, Gustafsson JA, Amado F, Lanari C \& Helguero LA 2013 Estrogen receptor $\beta$ growth-inhibitory effects are repressed through activation of MAPK and PI3K signalling in mammary epithelial and breast cancer cells. Oncogene 32 2390-2402. (doi:10.1038/onc.2012.261)

Domcke S, Sinha R, Levine DA, Sander C \& Schultz N 2013 Evaluating cell lines as tumour models by comparison of genomic profiles. Nature Communications 4 2126. (doi:10.1038/ncomms3126)

Duncan JS \& Litchfield DW 2008 Too much of a good thing: the role of protein kinase CK2 in tumorigenesis and prospects for therapeutic inhibition of CK2. Biochimica et Biophysica Acta 1784 33-47. (doi:10.1016/j.bbapap.2007.08.017)

Fujimura M, Katsumata N, Tsuda H, Uchi N, Miyazaki S, Hidaka T, Sakai M \& Saito S 2002 HER2 is frequently over-expressed in ovarian clear cell adenocarcinoma: possible novel treatment modality using recombinant monoclonal antibody against HER2, trastuzumab. Japanese Journal of Cancer research: Gann 93 1250-1257. (doi:10.1111/j.1349-7006.2002.tb01231.x)

Hedelin M, Lof M, Andersson TM, Adlercreutz H \& Weiderpass E 2011 Dietary phytoestrogens and the risk of ovarian cancer in the women's lifestyle and health cohort study. Cancer Epidemiology, Biomarkers \& Prevention 20 308-317. (doi:10.1158/1055-9965.EPI-10-0752)

Heldring N, Pike A, Andersson S, Matthews J, Cheng G, Hartman J, Tujague M, Strom A, Treuter E, Warner M et al. 2007 Estrogen receptors: how do they signal and what are their targets. Physiological Reviews $\mathbf{8 7}$ 905-931. (doi:10.1152/physrev.00026.2006)

Itamochi H, Kigawa J \& Terakawa N 2008 Mechanisms of chemoresistance and poor prognosis in ovarian clear cell carcinoma. Cancer Science 99 653-658. (doi:10.1111/j.1349-7006.2008.00747.x)
Jayson GC, Kohn EC, Kitchener HC \& Ledermann JA 2014 Ovarian cancer. Lancet 384 1376-1388. (doi:10.1016/S0140-6736(13)62146-7)

Jin Y, Li Y \& Pan L 2014 The target therapy of ovarian clear cell carcinoma. OncoTargets and Therapy 7 1647-1652. (doi:10.2147/OTT.S49993)

Kaku T, Ogawa S, Kawano Y, Ohishi Y, Kobayashi H, Hirakawa T \& Nakano H 2003 Histological classification of ovarian cancer. Medical Electron Microscopy 36 9-17. (doi:10.1007/s007950300002)

Khalifa MA, Mannel RS, Haraway SD, Walker J \& Min KW 1994 Expression of EGFR, HER-2/neu, P53, and PCNA in endometrioid, serous papillary, and clear cell endometrial adenocarcinomas. Gynecologic Oncology 53 84-92. (doi:10.1006/gyno.1994.1092)

Kuo KT, Mao TL, Jones S, Veras E, Ayhan A, Wang TL, Glas R, Slamon D, Velculescu VE, Kuman RJ et al. 2009 Frequent activating mutations of PIK3CA in ovarian clear cell carcinoma. American Journal of Pathology 174 1597-1601. (doi:10.2353/ajpath.2009.081000)

Lee YH, Yuk HJ, Park KH \& Bae YS 2013 Coumestrol induces senescence through protein kinase CKII inhibition-mediated reactive oxygen species production in human breast cancer and colon cancer cells. Food Chemistry 141 381-388. (doi:10.1016/j.foodchem.2013.03.053)

de Leeuw R, Neefjes J \& Michalides R 2011 A role for estrogen receptor phosphorylation in the resistance to tamoxifen. International Journal of Breast Cancer 2011 232435. (doi:10.4061/2011/232435)

Liu S, Hsieh D, Yang YL, Xu ZD, Peto C, Jablons DM \& You L 2013 Coumestrol from the national cancer Institute's natural product library is a novel inhibitor of protein kinase CK2. BMC Pharmacology \& Toxicology 14 36. (doi:10.1186/2050-6511-14-36)

Mabuchi S, Kawase C, Altomare DA, Morishige K, Sawada K, Hayashi M, Tsujimoto M, Yamoto M, Klein-Szanto AJ, Schilder RJ et al. 2009 mTOR is a promising therapeutic target both in cisplatin-sensitive and cisplatin-resistant clear cell carcinoma of the ovary. Clinical Cancer Research 15 5404-5413. (doi:10.1158/1078-0432.CCR-09-0365)

Mendoza MC, Er EE \& Blenis J 2011 The Ras-ERK and PI3K-mTOR pathways: cross-talk and compensation. Trends in Biochemical Sciences 36 320-328. (doi:10.1016/j.tibs.2011.03.006)

Musgrove EA \& Sutherland RL 2009 Biological determinants of endocrine resistance in breast cancer. Nature Reviews. Cancer 9 631-643. (doi:10.1038/nrc2713)

Obiorah IE, Fan P \& Jordan VC 2014 Breast cancer cell apoptosis with phytoestrogens is dependent on an estrogen-deprived state. Cancer Prevention Research 7 939-949. (doi:10.1158/1940-6207.CAPR-14-0061)

Oishi T, Itamochi H, Kudoh A, Nonaka M, Kato M, Nishimura M, Oumi N, Sato S, Naniwa J, Sato S et al. 2014 The PI3K/mTOR dual inhibitor NVP-BEZ235 reduces the growth of ovarian clear cell carcinoma. Oncology Reports 32 553-558. (doi:10.3892/or.2014.3268)

Patisaul HB \& Jefferson W 2010 The pros and cons of phytoestrogens. Frontiers in Neuroendocrinology 31 400-419. (doi:10.1016/j.yfrne.2010. 03.003)

Schmelzle T \& Hall MN 2000 TOR, a central controller of cell growth. Cell 103 253-262. (doi:10.1016/S0092-8674(00)00117-3)

Schoenroth LJ, Hart DA, Pollard KM \& Fritzler MJ 2004 The effect of the phytoestrogen coumestrol on the NZB/W F1 murine model of systemic lupus. Journal of Autoimmunity 23 323-332. (doi:10.1016/j.jaut.2004. 09.004)

Shimizu M \& Weinstein IB 2005 Modulation of signal transduction by tea catechins and related phytochemicals. Mutation Research 591 147-160. (doi:10.1016/j.mrfmmm.2005.04.010)

Siegel RL, Miller KD \& Jemal A 2015 Cancer statistics, 2015. CA: A Cancer Journal for Clinicians 65 5-29. (doi:10.3322/caac.21254)

Tan DS \& Kaye S 2007 Ovarian clear cell adenocarcinoma: a continuing enigma. Journal of Clinical Pathology 60 355-360. (doi:10.1136/jcp. 2006.040030)

Thigpen JT, Blessing JA, Ball H, Hummel SJ \& Barrett RJ 1994 Phase II trial of paclitaxel in patients with progressive ovarian carcinoma after platinum-based chemotherapy: a Gynecologic Oncology Group study. Journal of Clinical Oncology 12 1748-1753. 
Vaughan S, Coward JI, Bast RC Jr, Berchuck A, Berek JS, Brenton JD, Coukos G, Crum CC, Drapkin R, Etemadmoghadam D et al. 2011 Rethinking ovarian cancer: recommendations for improving outcomes. Nature Reviews. Cancer 11 719-725. (doi:10.1038/ nrc3144)

Virk-Baker MK, Nagy TR \& Barnes S 2010 Role of phytoestrogens in cancer therapy. Planta Medica 76 1132-1142. (doi:10.1055/ s-0030-1250074)
Yuan ZQ, Sun M, Feldman RI, Wang G, Ma X, Jiang C, Coppola D, Nicosia SV \& Cheng JQ 2000 Frequent activation of AKT2 and induction of apoptosis by inhibition of phosphoinositide-3-OH kinase/Akt pathway in human ovarian cancer. Oncogene 19 2324-2330. (doi:10.1038/sj.onc. 1203598)

Zhao E \& Mu Q 2011 Phytoestrogen biological actions on Mammalian reproductive system and cancer growth. Scientia Pharmaceutica 79 1-20. (doi:10.3797/scipharm.1007-15)

Received in final form 14 December 2015

Accepted 22 December 2015

Accepted Preprint published online 23 December 2015
Published by Bioscientifica Ltd. 